\title{
Modification of strength properties of soil-aggregate system on cement addition
}

\author{
Rahul Singh $^{1^{*}}$, Dhirendra Patel ${ }^{2}$ \\ ${ }^{1 * 2}$ Department of Civil Engineering, Kalaniketan Polytechnic, Jabalpur, MP, INDIA \\ "Corresponding Author: e-mail: rahulsp21@gmail.com, Tel +91-9039697530
}

\begin{abstract}
Addition of chemical or cementitious additives is very effective in increasing the strength of soil. The effectiveness of these additives depends on the soil treated and the amount of additive used. In the present work in place of soil alone Soil-Aggregate mix is taken into consideration and the same is tested for strength parameters by increasing doses of cement addition. Soil-Aggregate mixture can be effectively used as base and subbase layer of a flexible pavement system. For assessing strength parameters tests such as Density determination, CBR and UCS are done with varying doses of cement. Wetting and drying tests are also performed for durability of Soil-Aggregate mix. Result shows an increase in the CBR and UCS value of the soil on increasing cement doses to Soil-Aggregate mix. Also results of durability test shows that increasing doses of cement addition is helpful in reducing the loss in weight of Soil-Aggregate mix. Results of standard proctor test shows that cement addition to Soil-Aggregate mix helps in reducing OMC increasing MDD value of soil. The optimum dose is then selected based on test conducted and results obtained.
\end{abstract}

Keywords: Soil-aggregate mixtures, Cement, CBR,UCS,MDD, OMC, durability

DOI: http://dx.doi.org/10.4314/ijest.v9i3.1

\section{Introduction}

India is currently having a road network of 4.69 million kilometers. They carry almost 90 percent of the country's passenger traffic and 65 percent of its freight. National Highways and State Highways, comprising only 3\% of total road length, each carrying 40\% of the total road traffic [Indian Infrastructure: Roads and Bridges: Directory and Yearbook 2013, 2013]. The density of India's highway network of $1.03 \mathrm{~km}$ of highway per square kilometer of land is better than that of the United States $(0.66)$ and much greater than China (0.18) or Brazil (0.20) (IRF World Road Statistics, 2006). Cement stabilization involves the addition of varying amount of cement to modify the soil properties. The amount of cement needed to stabilize soil ranges from 3 to $16 \%$ (Bell, 1993) by dry weight of soil for desired properties. Mostly ordinary Portland cement is used for soil stabilization.

Strength and stability are major requirements for the pavement at present. In most of the cases the in-situ soil will not be having sufficient strength to bear the traffic load coming to it. If the in-situ soil is made usable through improvement techniques, this itself will considerably reduce the cost of pavement construction. Present work focuses on the effect of Cement on various engineering properties of the mixture formed by locally available soil and aggregate and also to find the optimum dose of additives which can give the increased value of various strength related parameters such as CBR, UCS also durability of soil-aggregate mixtures with varying doses of cement is checked by conducting wetting and drying test.

\section{Material and Methods}

Stabilization in a broad sense includes various methods incorporated for modifying the properties of a soil to enhance its performance. It is being used for a variety of engineering works, the most common application being in the construction of a pavement where the main objective is to increase the strength or stability of soil and to minimize the construction cost by effectively using locally available materials. 


\subsection{Soil and Aggregates}

Soil and Aggregates to be used are obtained locally. Before carrying out actual testing, it is required that the materials should meet up to the requirements. Soil and Aggregates are tested to the requirements according to IS: 2720 and MoRTH Specifications for Road and Bridge Works, Fifth Edition respectively.

Table 1 Properties of subgrade soil

\begin{tabular}{|c|c|}
\hline Soil Property & Result \\
\hline Liquid limit (\%) & 40 \\
\hline Plastic limit (\%) & 21 \\
\hline Optimum moisture content (OMC) & $14.7 \%$ \\
\hline Maximum dry density (MDD) & $1.683 \mathrm{~g} / \mathrm{cc}$ \\
\hline Classification (USCS) & $\mathrm{CL}$ \\
\hline
\end{tabular}

It is required that the aggregate should possess strength, durability and compatibility so that effective mix can be prepared with the soil. Strength is measured by hardness and toughness, durability in terms of soundness test, cleanliness and water absorption. Particle shape test not only will affect the mixture preparation but will also determine the strength of aggregates under frequent traffic load.

\subsection{Cement}

Portland cements are hydraulic cements which through hydration set and harden by reacting with water, through hydration. Portland cement is manufactured by intimately mixing together calcareous and argillaceous and other silica, alumina or iron oxide bearing materials and burning them at a clinkering temperature and grinding the resultant clinker. This makes the ordinary Portland cement. The cement used in present work is OPC-43 which possesses 28 days compressive strength as $43 \mathrm{Mpa}$.

\section{Experimental Program and Results}

\subsection{Aggregate gradation for the soil-aggregate mixture}

For carrying out the process of making soil-aggregate sample we need to know about the various gradation which makes use in soil- aggregate mixture. The gradation for the present work was chosen from ASTM D1241 -07 'Standard Specification for Materials for Soil-Aggregate Subbase, Base, and Surface courses'. Two types of mixtures are specified in the code for soil aggregate mixtures:

Type I Mixtures shall consist of stone, gravel, or slag with natural or crushed sand and fine mineral particles passing 75- $\mathrm{m}$ sieve and shall conform to the requirements of Table 1of ASTM D1241 -07for Gradation A, B, C, or D.

Type II Mixtures shall consist of natural or crushed sand with fine mineral particles passing a 75- msieve, with or without gravel, stone, or slag, and shall conform to the requirements of Table 1 of ASTM D1241 -07for Gradation E or F. In the present work Gradation C of ASTM D1241 -07was chosen as maximum size of aggregate is restricted to $25 \mathrm{~mm}$ and it covers most of the size range with a good percentage.

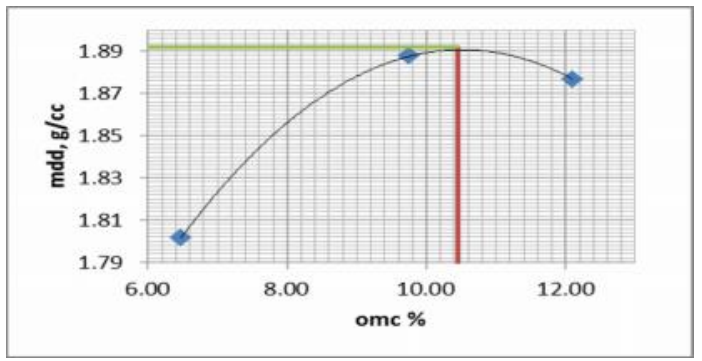

Figure 1. Variation of MDD with OMC for untreated soil

\subsection{Standard Proctor compaction test on untreated Soil - Aggregate mixture}

Variation of MDD with OMC for a mixture of 50\% soil and 50\% aggregate without additive is shown by the above graph 1 and values for the same is shown in the Table 2 below. 
Table 2. Soil properties of untreated soil

\begin{tabular}{|c|c|c|}
\hline \multicolumn{3}{|c|}{$50 \mathrm{~S} / 50 \mathrm{~A}$} \\
\hline $\begin{array}{c}\text { Bulk density } \\
(\mathrm{g} / \mathrm{cc})\end{array}$ & $\begin{array}{c}\mathrm{W}_{\mathrm{c}} \\
(\%)\end{array}$ & Dry density $(\mathrm{g} / \mathrm{cc})$ \\
\hline 1.918 & 6.47 & 1.80 \\
\hline 2.066 & 9.75 & 1.89 \\
\hline 2.104 & 12.11 & 1.88 \\
\hline
\end{tabular}

Note $: \mathrm{W}_{\mathrm{c}}=$ Water Content

3.3 Standard Proctor compaction test Soil - Aggregate mixture treated with Cement

Table 3. Water content and dry density for different doses of Cement

\begin{tabular}{|c|c|c|c|c|c|c|c|c|}
\hline \multicolumn{3}{|c|}{$2 \%$ cement } & \multicolumn{3}{c|}{$4 \%$ cement } & \multicolumn{3}{c|}{$6 \%$ cement } \\
\hline $\begin{array}{c}\text { Bulk } \\
\text { density } \\
(\mathrm{g} / \mathrm{cc})\end{array}$ & Wc $(\%)$ & $\begin{array}{c}\text { Dry } \\
\text { density } \\
(\mathrm{g} / \mathrm{cc})\end{array}$ & $\begin{array}{c}\text { Bulk } \\
\text { density } \\
(\mathrm{g} / \mathrm{cc})\end{array}$ & Wc $(\%)$ & $\begin{array}{c}\text { Dry } \\
\text { density } \\
(\mathrm{g} / \mathrm{cc})\end{array}$ & $\begin{array}{c}\text { Bulk } \\
\text { density } \\
(\mathrm{g} / \mathrm{cc})\end{array}$ & Wc (\%) & $\begin{array}{c}\text { Dry } \\
\text { density } \\
(\mathrm{g} / \mathrm{cc})\end{array}$ \\
\hline 1.787 & 8.10 & 1.65 & 1.829 & 7.94 & 1.69 & 1.821 & 7.89 & 1.69 \\
\hline 1.854 & 9.70 & 1.69 & 1.876 & 9.48 & 1.71 & 1.894 & 9.48 & 1.73 \\
\hline 1.874 & 11.61 & 1.68 & 1.907 & 12.18 & 1.70 & 1.93 & 11.87 & 1.73 \\
\hline
\end{tabular}

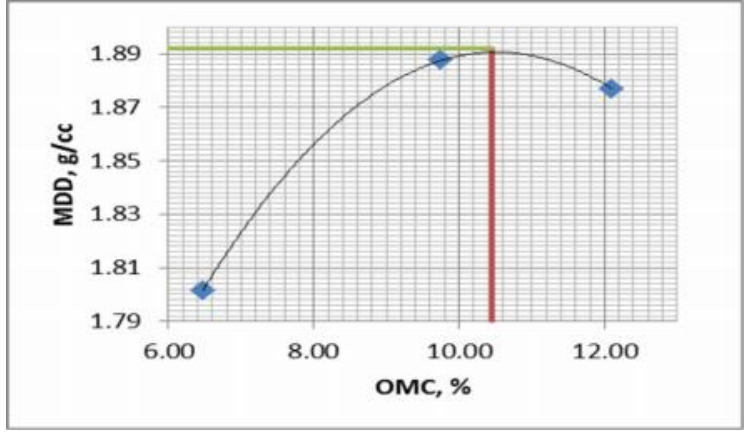

Figure 2. Variation of MDD with OMC for 50S/50A combination

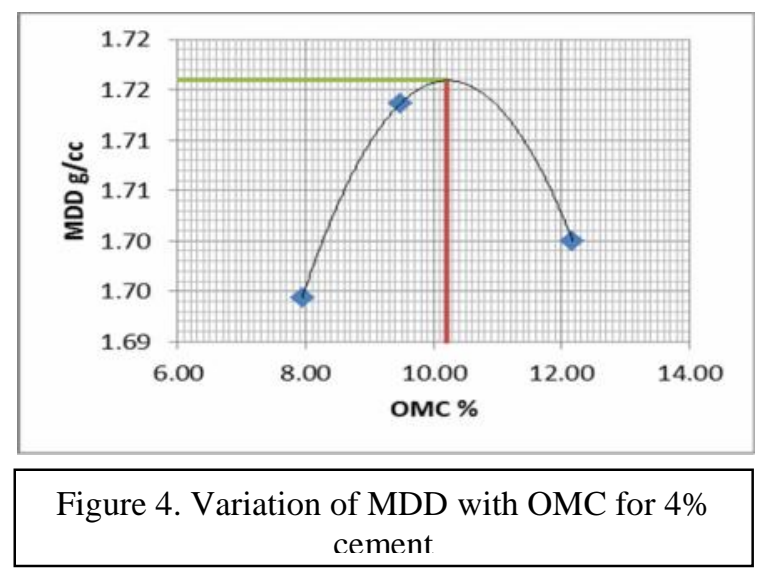

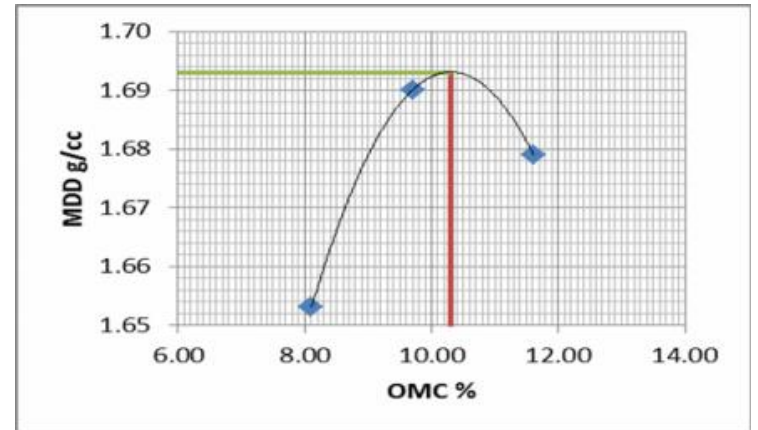

Figure 3. Variation of MDD with OMC for 2\% cement

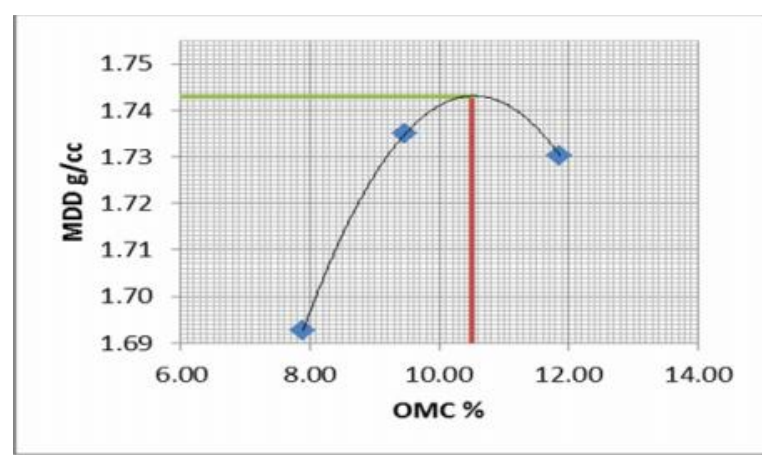

Figure 5. Variation of MDD with OMC for $6 \%$ cement

The above Figures $(2,3,4,5)$ show the variation of MDD with OMC with increasing doses of cement from $2 \%$ to $6 \%$ and it can be seen that the MDD increases with higher doses of cement. 
Table 4.Results of MDD \& OMC for various dose of Cement

\begin{tabular}{|c|c|c|}
\hline \multirow{2}{*}{ Material } & \multicolumn{2}{|c|}{ Results } \\
\cline { 2 - 3 } & OMC (\%) & MDD (g/cc) \\
\hline Soil-Aggregate mixture at 50\% by 50\% each & 10.45 & 1.892 \\
\hline Mixture with 2\% Cement & 10.3 & 1.693 \\
\hline Mixture with 4 \% Cement & 10.2 & 1.716 \\
\hline Mixture with 6\% Cement & 10.5 & 1.738 \\
\hline
\end{tabular}

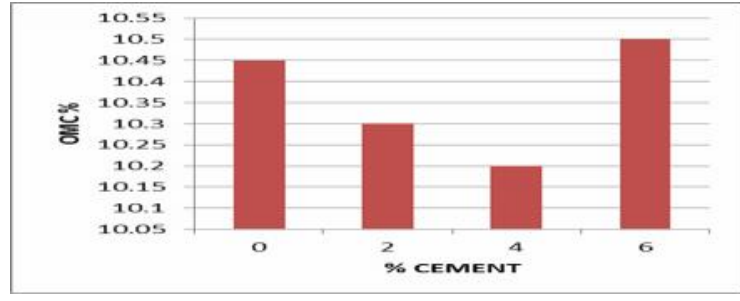

Figure $6 \mathrm{OMC}$ for different doses of cement

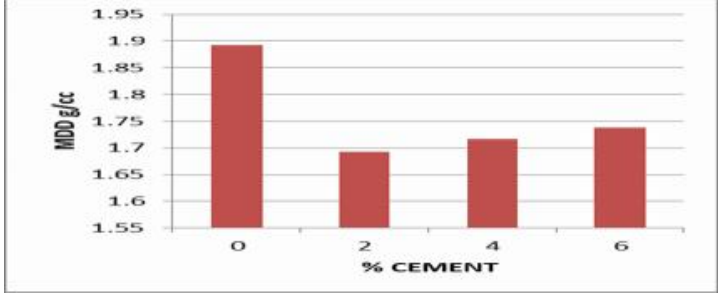

Figure 7 MDD for different doses of cement

The above Figures $(6,7)$ show the variation of OMC and MDD separately with increasing doses of cement and it can be seen that OMC decrease for initial doses of cement from 0 to $4 \%$ cement but increases for higher dose of $6 \%$ and in case of MDD there is always an increase in the value when we go for higher doses of cement.

\subsection{CBR test on Soil-Aggregate mixture treated with Cement}

CBR test was performed with increasing cement content of $2 \%$ to $6 \%$ by weight of the mix. Cement used in the test was ordinary Portland cement grade 43 (OPC-43). Observed CBR value is presented in the table below.

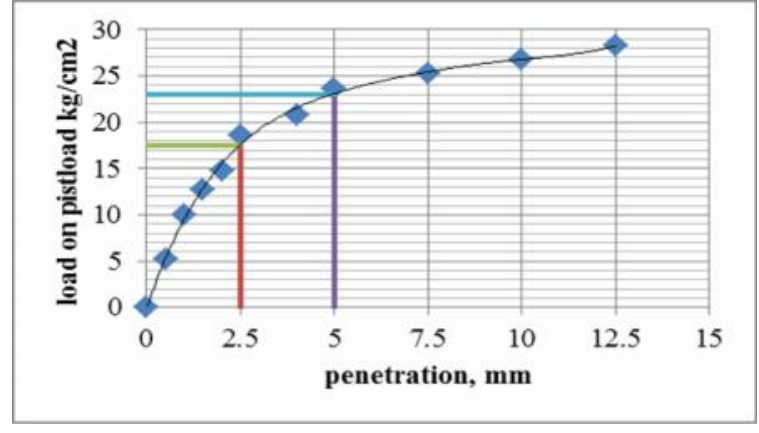

Figure 8 Load vs penetration curve for $50 \mathrm{~S} / 50 \mathrm{~A}$ without Cement

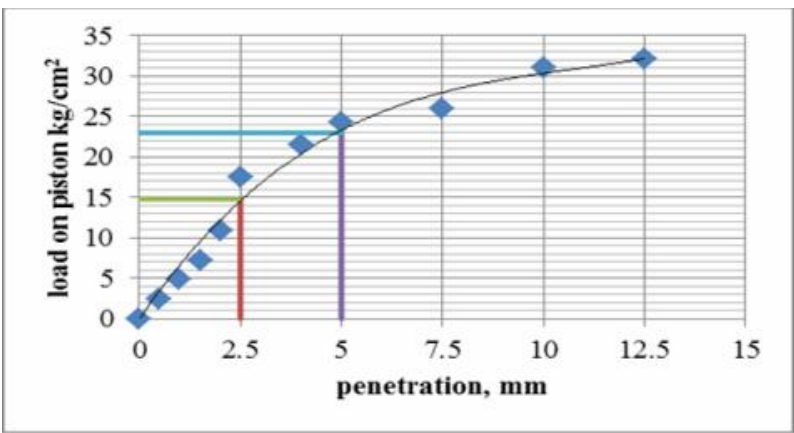

Figure 9 Load vs penetration curve for $2 \%$ cement

Table 5 Percentage CBR for different doses of Cement for unsoaked condition

\begin{tabular}{|c|c|}
\hline Combination & CBR Value \% \\
\hline 50S/50A & 25 \\
\hline Mix with 2\% cement & 21.90 \\
\hline Mix with 4\% cement & 23.81 \\
\hline Mix with 6\% cement & 27.14 \\
\hline
\end{tabular}




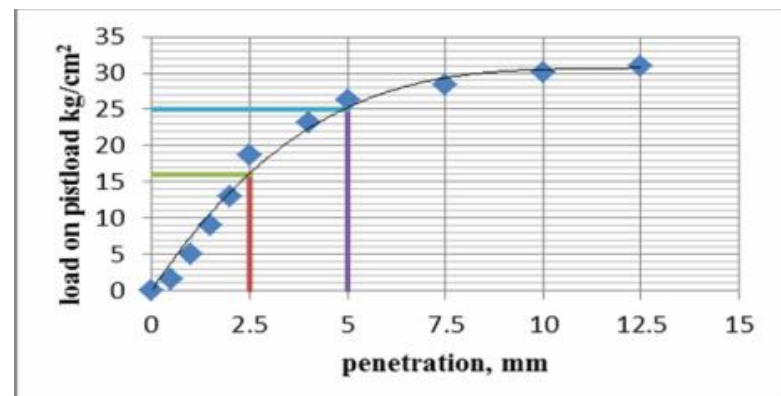

Figure 10. Load vs penetration curve for $4 \%$ cement

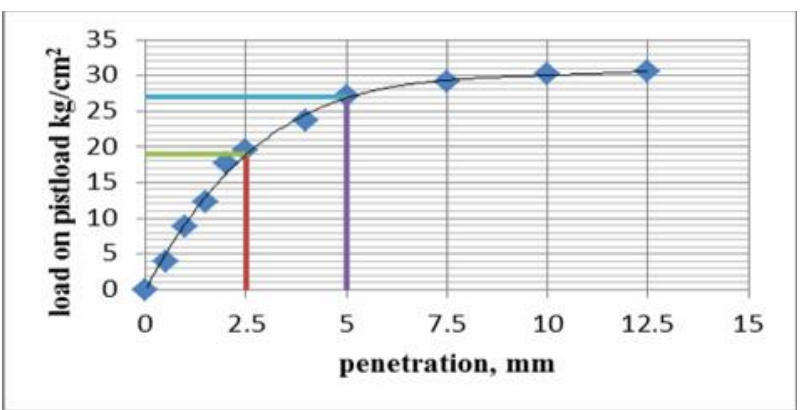

Figure 11. Load vs penetration curve for $6 \%$ cement

The above Figures $(8,9,10,11)$ shows the variation of CBR without any cement and then after addition of increasing doses of cement from $2 \%$ to $6 \%$ for unsoaked condition and corresponding values are given in the table 5 and from this we can say that cement has a good effect in increasing the value of CBR the value increases for increasing doses of cement.

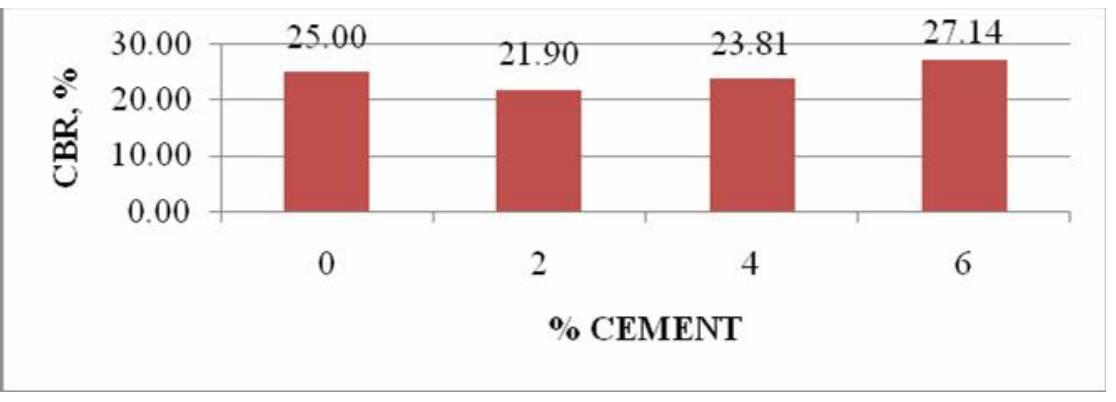

Figure 12 Variation of CBR with cement

\subsection{CBR test on Soil-Aggregate mixture treated with Cement for soaked condition}

Table 6 Percentage CBR for different doses of Cement for soaked condition

\begin{tabular}{|c|c|}
\hline Combination & CBR $(\%)$ \\
\hline 50S/50A & 12.14 \\
\hline Mix with 2\% cement & 12.29 \\
\hline Mix with 4\% cement & 15.00 \\
\hline Mix with 6\% cement & 15.71 \\
\hline
\end{tabular}

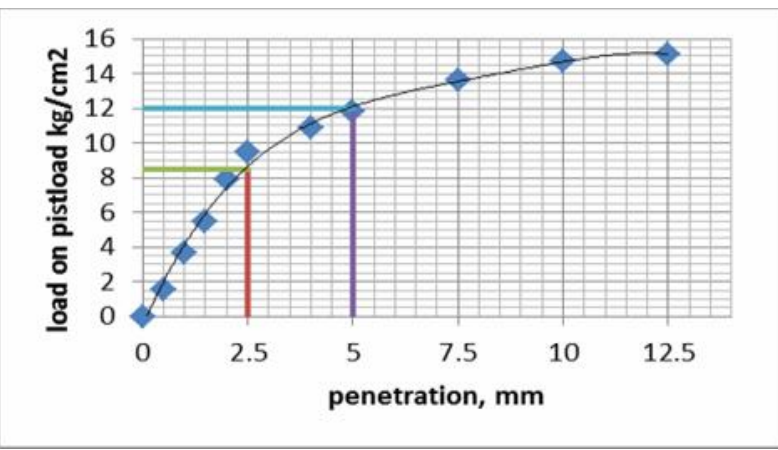

Figure 13. Load vs penetration curve for $50 \mathrm{~S} / 50 \mathrm{~A}$ without Cement

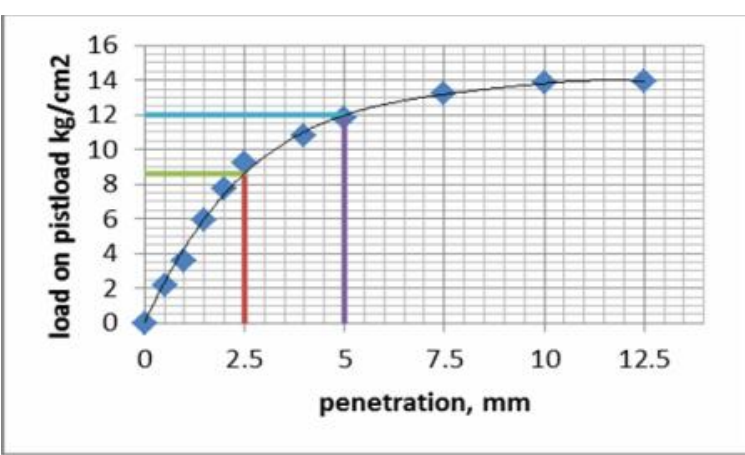

Figure 14. Load vs penetration curve for $2 \%$ cement 


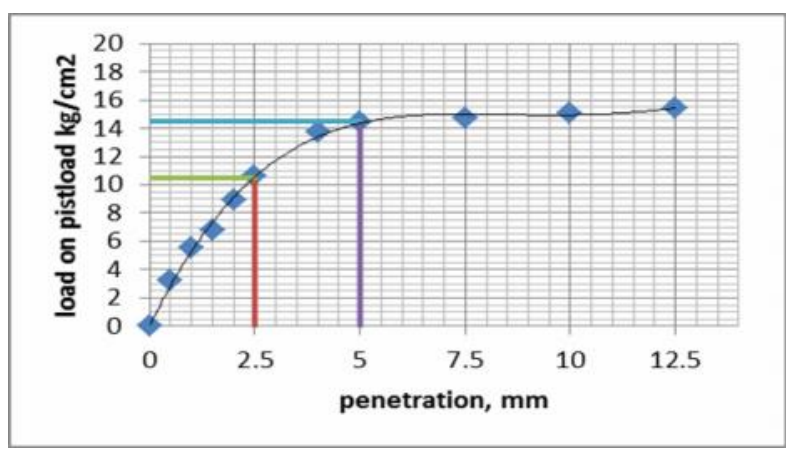

Figure 15. Load vs penetration curve for $4 \%$

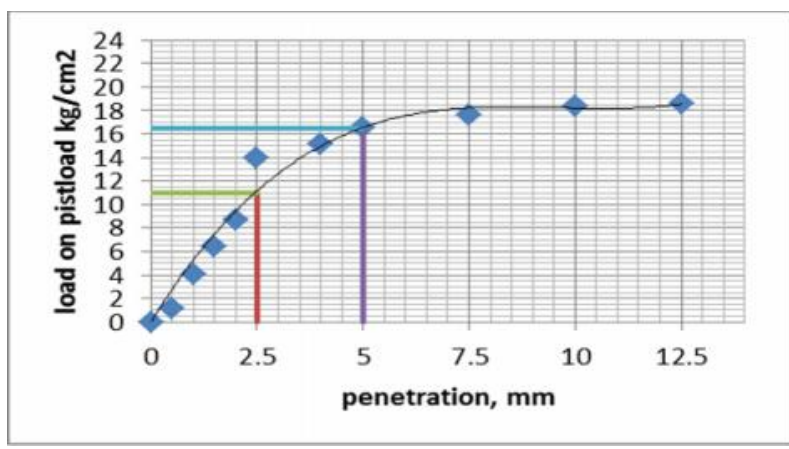

Figure 16. Load vs penetration curve for $6 \%$ cement

From the above Figures $(13,14,15,16)$ the variations of CBR can be seen for the case of plain soil and aggregate without any cement and then after addition of increasing doses of cement from $2 \%$ to $6 \%$ for soaked condition and corresponding values are given in the Tables 3.4 and from this we can say that cement has a good effect in increasing the value of CBR the value increases for increasing doses of cement (Figure 17).

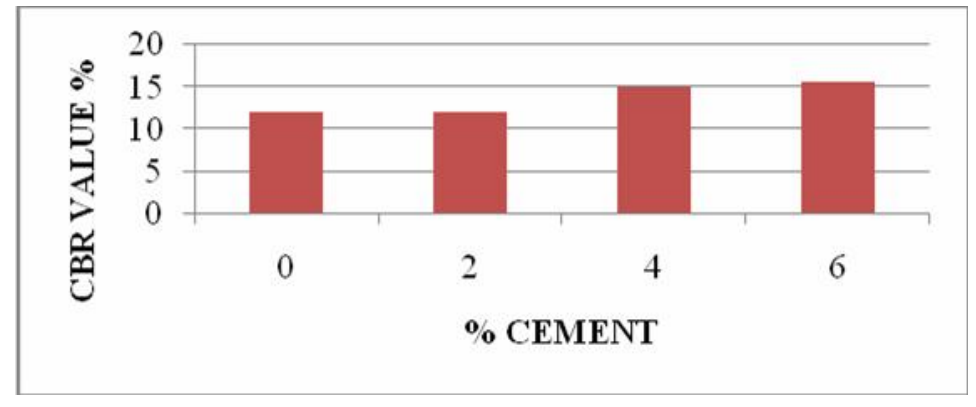

Figure 17 Variation of CBR with cement

\subsection{Unconfined Compressive Strength Test on Soil- Aggregate Mixture}

Unconfined Compressive Strength Test on Soil- Aggregate Mixture was performed according to IS 4332:1970 (Part 5) on a 15 $\mathrm{cm}$ size cube (Figure 18). Test samples were prepared according to section 13.2 based on constant compactive efforts as described below. The soil shall be prepared as described in IS: 4332(Part I) -1967.The mould shall be assembled on its base plate, and another mould, less base plate, placed squarely on top. A quantity of soil sufficient to give a specimen of 150 to $165 \mathrm{~mm}$ depth after compaction (that is about $8 \mathrm{~kg}$ ) shall be compacted into the mould in three equal layers, each layer being given 35 blows of the rammer dropped from a height of $450 \mathrm{~mm}$ above the soil. The blows shall be uniformly distributed over the surface of each layer, which shall be scarified with the palette knife before the next layer is added. After removing the upper mould, excess material shall be struck off level with the top of the lower mould by means of a straightedge, and any irregularities shall be filled with fine material from the same sample. The mould containing the specimen shall then be covered with a metal plate and stored at a temperature of $27 \pm 2{ }^{\circ} \mathrm{C}$ until the following day when the specimen shall be removed from the mould for further curing. The specimen shall then be weighed to the nearest $1 \mathrm{~g}$. Curing of samples are done at $27 \pm 2^{\circ} \mathrm{C}$ for 3 days and loss in weight are noted down (Figure 19). Any specimen that has lost more than $10 \mathrm{~g}$ in weight during the storage period shall be discarded (IS $4332: 1970$ Part 5)
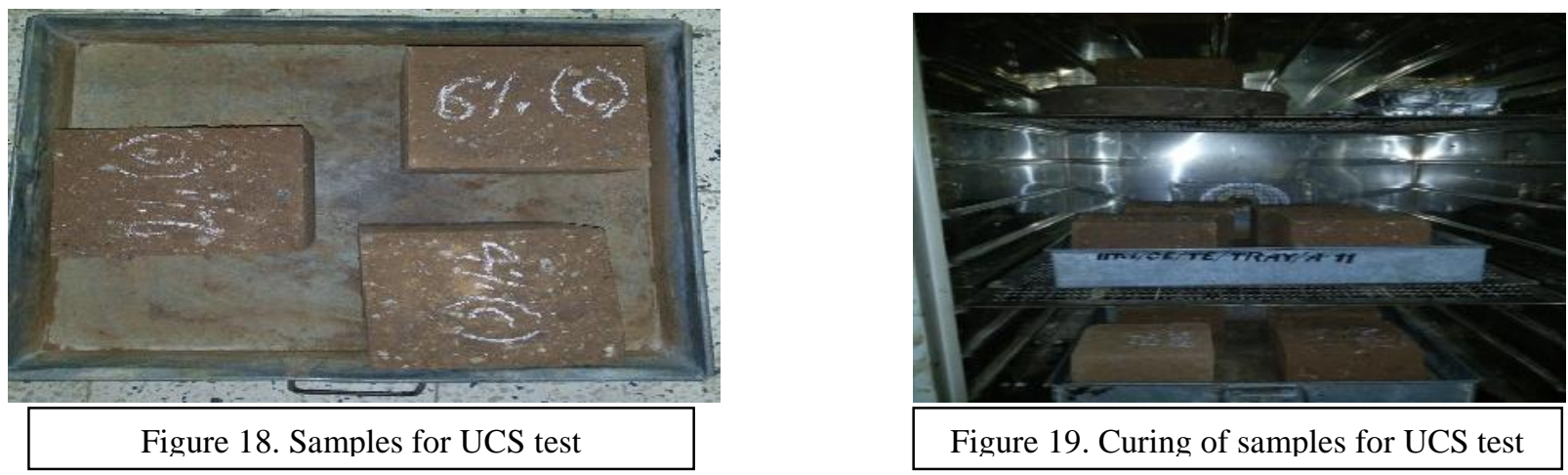


\subsection{Compressive Strength test on the Test Samples}

The specimen shall then be placed centrally on the lower platen of the compression testing machine in such a manner that the load shall be applied to opposite sides of the cube as cast, that is not to the top and bottom (Figure 20). The load shall be applied without shock and increased continuously at a rate of approximately $35 \mathrm{kgf} / \mathrm{cm} /$ minute till the resistance of the cube to the increasing load breaks-down and no greater load can be sustained. The maximum load exerted by the machine can be recorded. The unconfined compressive strength of the specimen shall be calculated from the formula

$$
U C S=\frac{P}{A}
$$

$\mathrm{P}=$ maximum load in $\mathrm{kg}$

$\mathrm{A}=$ Area of cross section of sample in $\mathrm{cm}^{2}$.

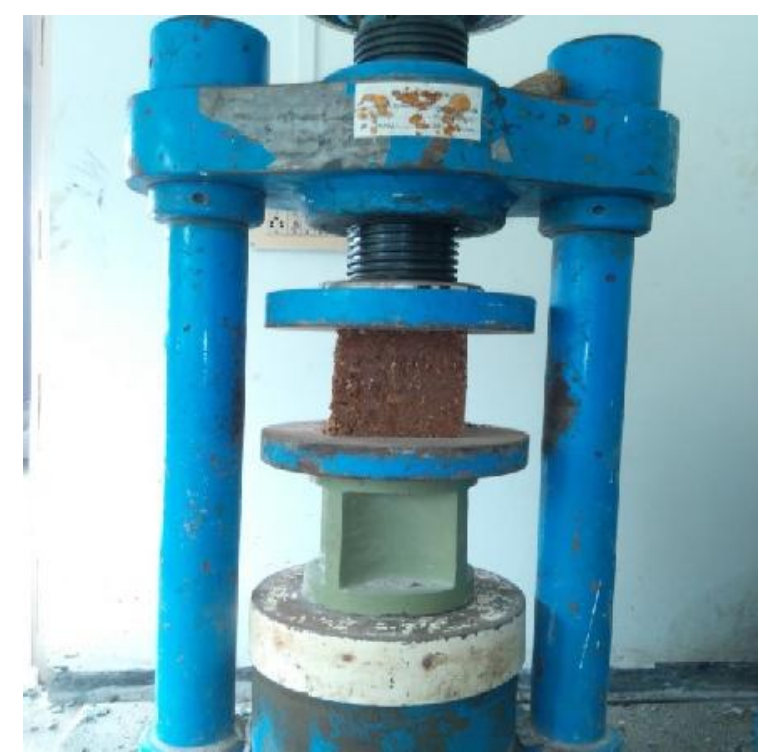

Figure 20. Compressive Strength Test Apparatus

3.8 UCS of untreated Soil-Aggregate mixture

Set 1

\begin{tabular}{|c|c|c|c|c|c|}
\hline Combination & Weight $(\mathrm{g})$ & Volume $(\mathrm{cc})$ & Density $(\mathrm{g} / \mathrm{cc})$ & Load $(\mathrm{KN})$ & UCS $(\mathrm{Mpa})$ \\
\hline 50S/50A & 6333 & 3375 & 1.88 & 22 & 0.978 \\
\hline
\end{tabular}

Set 2

\begin{tabular}{|c|c|c|c|c|c|}
\hline Combination & Weight $(\mathrm{g})$ & Volume(cc) & $\operatorname{Density}(\mathrm{g} / \mathrm{cc})$ & $\operatorname{Load}(\mathrm{KN})$ & UCS (Mpa) \\
\hline $50 \mathrm{~S} / 50 \mathrm{~A}$ & 6423 & 3375 & 1.90 & 22 & 0.978 \\
\hline \multicolumn{6}{|c|}{ Set 3} \\
\hline Combination & Weight $(\mathrm{g})$ & Volume(cc) & $\operatorname{Density}(\mathrm{g} / \mathrm{cc})$ & Load(KN) & UCS (Mpa) \\
\hline $50 \mathrm{~S} / 50 \mathrm{~A}$ & 6448 & 3375 & 1.91 & 24 & 1.067 \\
\hline
\end{tabular}

\begin{tabular}{|c|c|}
\hline Combinations & Average UCS (Mpa) \\
\hline $50 \mathrm{~S} / 50 \mathrm{~A}$ & 1.007 \\
\hline
\end{tabular}

Table 7 UCS for different doses of Cement

\begin{tabular}{|c|c|}
\hline \% Cement & Average UCS (Mpa) \\
\hline 0 & 1.007 \\
\hline 2 & 1.259 \\
\hline 4 & 1.422 \\
\hline 6 & 1.481 \\
\hline
\end{tabular}




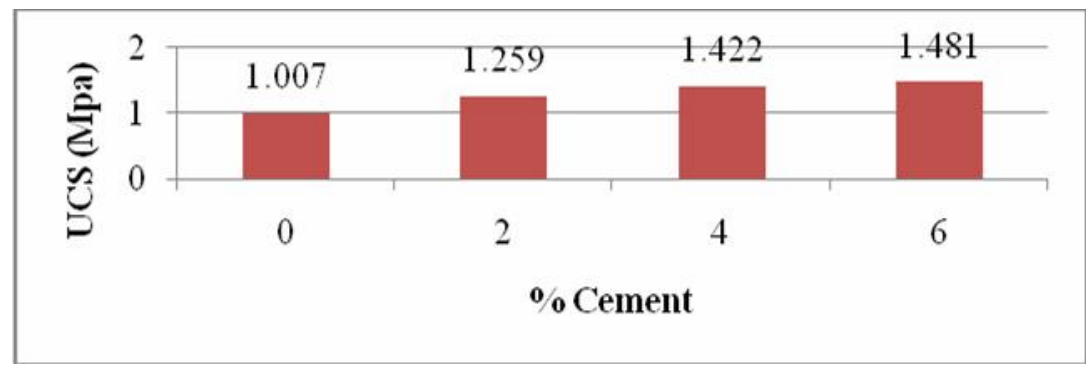

Figure 21. Variation of UCS with cement

From Figure 21 it can be concluded that cement has a good effect in increasing the UCS values of Soil-Aggregate mixture as values of UCS increases with higher doses of cement.

\subsection{Durability test (Drying and Wetting test)}

Test for durability of mix was checked from cylindrical sample having $1000 \mathrm{cc}$ volume of soil-aggregate with varying cement content of $2 \%$ cement by weight of the mix to $6 \%$ cement by weight of the mix after 12 cycles of drying and wetting. The maximum weight loss during each successive cycle and the maximum weight loss during 12 cycles were calculated and compared with recommendation given Portland Cement Association (PCA) for maximum soil-cement loss.

Table 8. Cumulative weight loss v/s no of cycles for different doses of cement

\begin{tabular}{|c|c|c|c|}
\hline \multirow{2}{*}{ Cycle no } & \multicolumn{3}{|c|}{ Cumulative weight loss (\%) } \\
\cline { 2 - 4 } & For 2\% cement & For 4\% cement & For 6\% cement \\
\hline 1 & 0.76 & 0.37 & 0.51 \\
\hline 2 & 1.63 & 0.70 & 0.99 \\
\hline 3 & 2.48 & 1.17 & 1.36 \\
\hline 4 & 2.95 & 1.57 & 1.77 \\
\hline 5 & 3.63 & 1.94 & 2.08 \\
\hline 6 & 4.08 & 2.57 & 2.60 \\
\hline 7 & 4.69 & 3.04 & 3.10 \\
\hline 8 & 5.49 & 3.64 & 3.47 \\
\hline 9 & 5.88 & 4.32 & 4.04 \\
\hline 10 & 6.60 & 4.96 & 4.51 \\
\hline 11 & 7.32 & 5.52 & 5.08 \\
\hline 12 & 7.90 & 6.05 & 5.67 \\
\hline
\end{tabular}

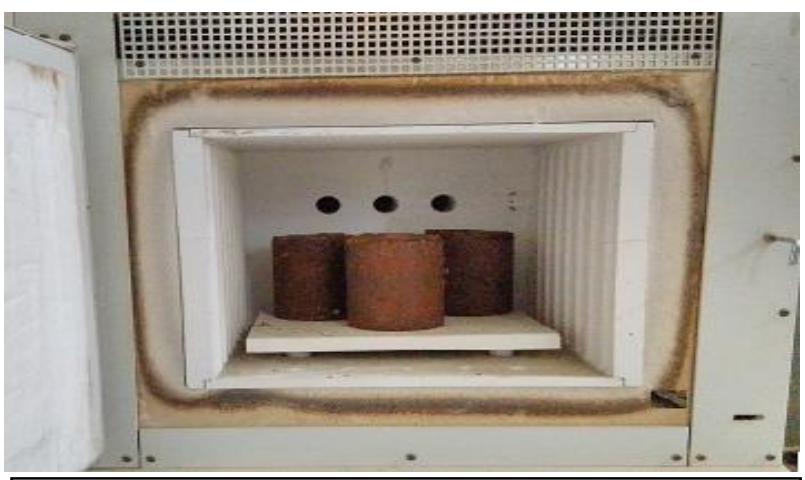

Figure 22. Curing of samples for Durability test

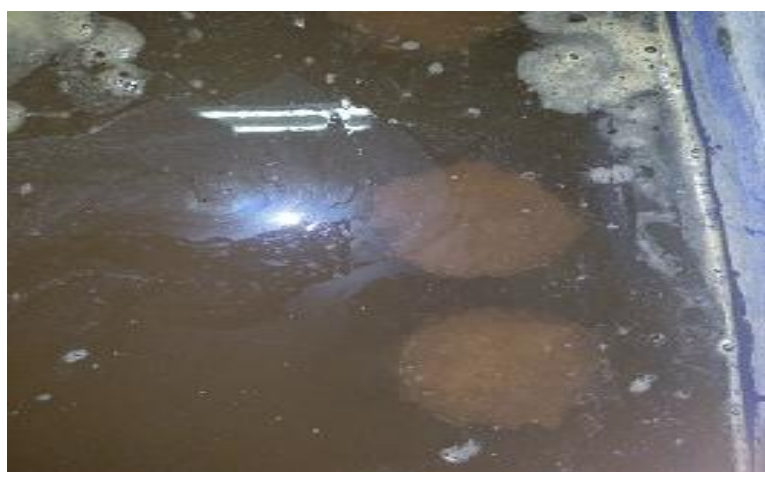

Figure 23. Immersion of samples in water for 5 hours 


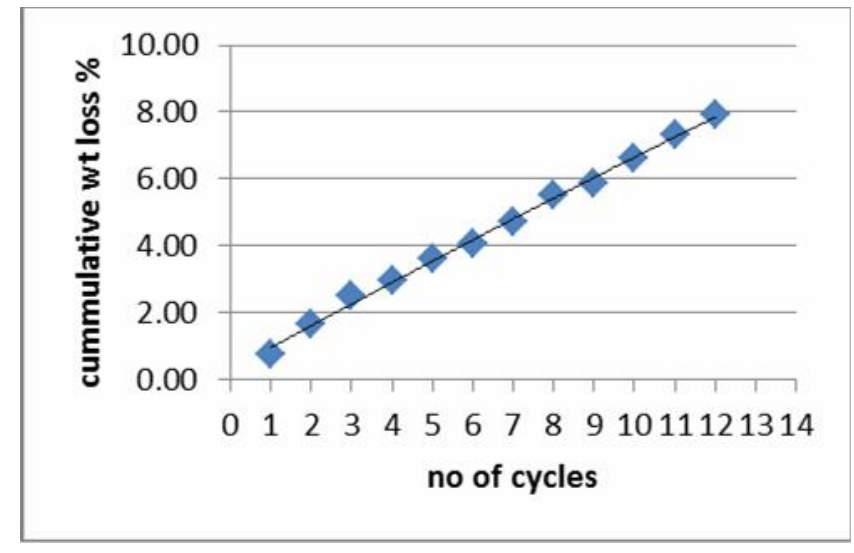

Figure 24. Curve of cumulative weight loss with no of cycles for $2 \%$ cement

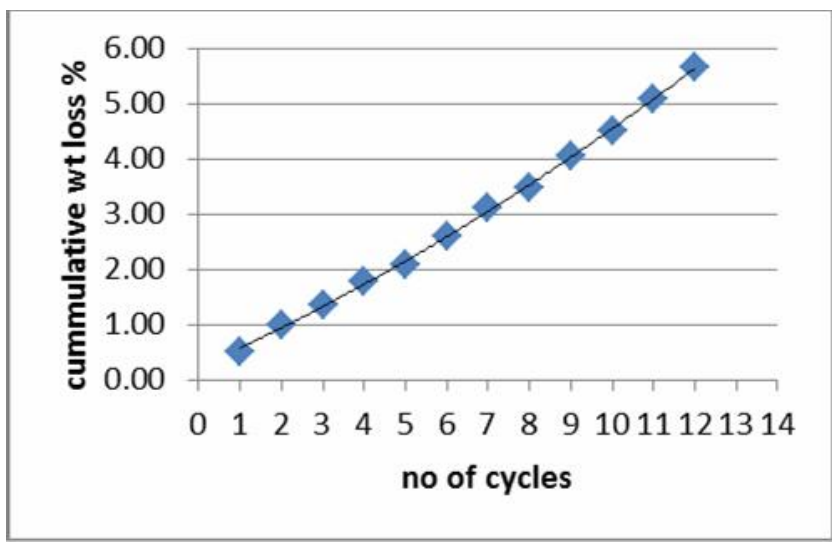

Figure 26. Curve of cumulative weight loss with no of cycles for $6 \%$ cement

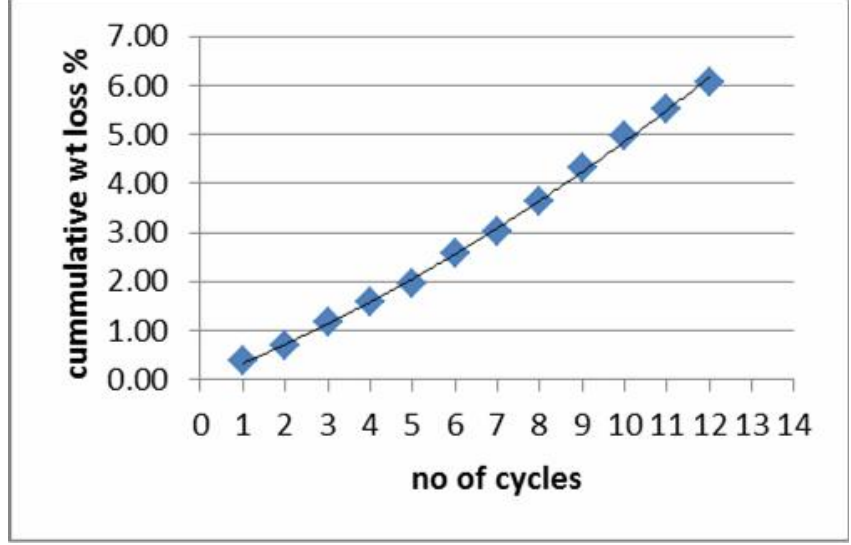

Figure 25. Curve of cumulative weight loss with no of cycles for $4 \%$ cement

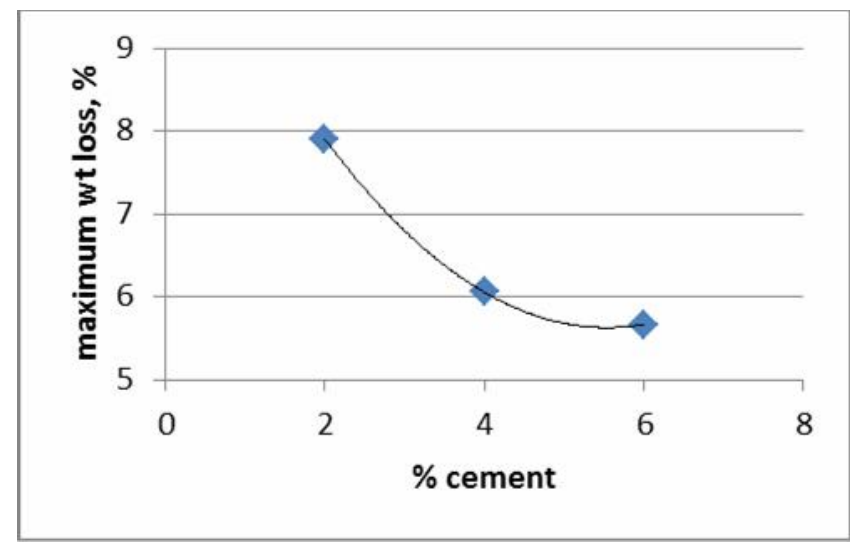

Figure 27. Variation of weight loss with cement

From the above Figures $(24,25,26,27)$ it can be seen that addition of cement helps in reduction of cumulative weight loss and if the doses of cement in increased then loss in weight further reduces.

\section{Conclusions}

The following are the conclusions from the study:

- Cement addition to soil aggregate mixture resulted in decrease in OMC for 2 and 4 percent doses while it suddenly increases with $6 \%$ dose of cement. In case of MDD the result shows a steady increase in its value with increasing doses of cement.

- Cement helps in increasing the MDD of the mix with increasing doses of the mix while OMC reduces for initial doses and increases for higher doses.

- From the results it can be concluded that addition of aggregates in the soil increases the CBR value of the soil and the value further increases with increasing proportion of aggreagates for both soaked and unsoaked conditions.

- Increasing doses of cement in the soil-aggregate mix increases CBR value of mix for both soaked and unsoaked conditions but for soaked condition increase in marginal for higher dose, so we can say that $6 \%$ cement by weight of the mix is optimum dose of cement.

- Cement has a very good effect in increasing UCS value of the soil-aggregate mix as the value increase rapidly with increasing cement content and is maximum for a dose of $6 \%$. Hence it can be regarded as its optimum dose. 
Samples for durability tests were made with varying cement content of $2 \%$ to $6 \%$ by weight of the mix and cumulative weight loss by scratching with a wire brush with increasing no of cycles from 1 to 12 of wetting and drying were noted down and plot shows that as the no of cycle progresses loss in weight occurs continuously. The cumulative weight loss for $2 \%, 4 \%, 6 \%$ cement addition are $7.90 \%, 6.05 \%, 5.67 \%$ respectively which indicates that with increasing cement content loss in weight decreases as cement makes the bond between soil and aggregate more strong with its higher percentage addition. Also it can be said that cumulative weight loss for $2 \%$ cement content was $7.90 \%$ which is beyond the limit suggested by Portland cement association (PCA) so we can say that $2 \%$ cement addition is not recommended as the tests results fails the required limit. Present work focuses on equal proportion of soil aggregate mix. However more studies can be further done on different proportion of soil and aggregate to present a more wide range of comparison of the results and better presentation of results.

\section{References}

Aiban, S.A., Al-Ahmadi, H.M., Asi, I.M., Siddique, Z.U., Al-Amoudi, O.S.B., 2006, Effect of geotextile and cement on the performance of sabkha subgrade, Building and Environment, Vol. 41, No. 6, pp. 807-820.

Ban, H., \& Park, S. W. 2014, Characteristics of modified soil-aggregate system and their application in pavements, KSCE Journal of Civil Engineering, Vol. 18, No. 6, pp. 1672-1678.

Basha, E. A., Hashim, R., Mahmud, H. B., \& Muntohar, A. S. 2005, Stabilization of residual soil with rice husk ash and cement. Construction and Building Materials, Vol. 19, No. 6, pp. 448-453.

Cetin, B., Aydilek, A. H., \& Guney, Y. 2010, Stabilization of recycled base materials with high carbon fly ash, Resources, Conservation and Recycling, Vol. 54, No. 11, pp. 878-892.

Madurwar, K. V., Dahale, P. P., \& Burile, A. N. 2013, Comparative study of black cotton soil stabilization with RBI Grade 81 and sodium silicate, International Journal of Innovative Research in Science, Engineering and Technology, Vol. 2, No. 2, pp. 493499.

Mekkawy, M. M., White, D. J., Suleiman, M. T., \&Jahren, C. T. 2011, Mechanically reinforced granular shoulders on soft subgrade: Laboratory and full scale studies, Geotextiles and Geomembranes, Vol. 29, No. 2, pp. 149-160.

Noor, M. J. M. L. 1994, Durability and strength characteristics of cement stabilized modified Melaka series, Journal of Islamic Academy of Sciences, Vol. 7, No. 2, pp. 137-141.

Poon, C. S., \& Chan, D. 2006, Feasible use of recycled concrete aggregates and crushed clay brick as unbound road sub-base, Construction and Building Materials, Vol. 20, No. 8, pp. 578-585.

Riaz, S., Aadil, N., \& Waseem, U. 2014, Stabilization of subgrade soils using cement and lime: a case study of Kala Shah Kaku, Lahore, Pakistan, Pakistan Journal of Science, Vol. 66, No. 1, pp. 39-44.

Yoon, S., \& Abu-Farsakh, M. 2009, Laboratory investigation on the strength characteristics of cement-sand as base material, KSCE Journal of Civil Engineering, Vol. 13, No. 1, pp. 15-22.

\section{Biographical notes}

Rahul Singh and Dhirendra Patel are currently of the Department of Civil Engineering, Kalaniketan Polytechnic, Jabalpur, MP, India.

Received June 2016

Accepted May 2017

Final acceptance in revised form June 2017 